\title{
Characteristics of Visual-Perceptual Function Measured by the Motor-Free Visual Perception Test-3 in Korean Adults
}

\author{
A-Reum Han, $\mathrm{MD}^{1}$, Doo-Yung Kim, $\mathrm{MD}^{2}$, Tae-Woong Choi, $\mathrm{MD}^{1}$, Hyun-Im Moon, $\mathrm{MD}^{1}$, \\ Byung-Joo Ryu, $\mathrm{MD}^{3}$, Seung-Nam Yang, MD, $\mathrm{PhD}^{1}$, Sung-Bom Pyun, $\mathrm{MD}, \mathrm{PhD}^{1}$
}

\begin{abstract}
${ }^{1}$ Department of Physical Medicine and Rehabilitation, Korea University College of Medicine, Seoul; ${ }^{2}$ Department of Physical Medicine and Rehabilitation, National Rehabilitation Center, Seoul; ${ }^{3}$ Department of Physical Medicine and Rehabilitation, Sahmyook Medical Center, Seoul, Korea
\end{abstract}

Objective To adapt and standardize the Motor-Free Visual Perception Test-3 (MVPT-3) to Koreans and investigate the change in visual-perceptual function using the MVPT-3 in healthy Korean adults.

Methods The Korean version of the MVPT- 3 was developed through a cross-cultural adaptation process according to 6 steps, including translation, reconciliation, back translation, cognitive debriefing, feedback, and final reconciliation. A total of 321 healthy Korean volunteers (mean age, 51.05 years) were recruited. We collected participant demographic data, such as sex, age, and years of education, and performed the Korean version of the Mini-Mental State Examination (K-MMSE) and MVPT-3. Internal consistency of the MVPT-3 and the relationships between demographic data, K-MMSE and MVPT-3 scores were analyzed. The results of this study were compared with published data from western countries including the United States and Canada.

Results Total score on the MVPT- 3 was positively correlated with years of education $(\mathrm{r}=0.715, \mathrm{p}<0.001)$ and K-MMSE score $(\mathrm{r}=0.718, \mathrm{p}<0.001)$. However, it had a negative correlation with age $(\mathrm{r}=-0.669, \mathrm{p}<0.001)$. A post-hoc analysis of MVPT-3 scores classified age into 5 groups of $\leq 49,50-59,60-69,70-79$, $\geq 80$ years and years of education into 4 groups of $0,1-9,10-12, \geq 13$ years. No significant differences in MVPT-3 scores were observed according to sex or country.

Conclusion Visual perception was significantly influenced by age, years of education, and cognitive function. Reference values for the MVPT-3 provided in this study will be useful for evaluating and planning a rehabilitation program of visual perceptual function in patients with brain disorders.

Keywords Visual perception, Cognition disorders, Reference standards, Brain diseases

Received April 3, 2014; Accepted June 18, 2014

Corresponding author: Sung-Bom Pyun

Department of Physical Medicine and Rehabilitation, Korea University Anam Hospital, Korea University College of Medicine, 73 Inchon-ro, Seongbukgu, Seoul 136-705, Korea

Tel: +82-2-920-6471, Fax: +82-2-929-9951, E-mail: rmpyun@korea.ac.kr

(c) This is an open-access article distributed under the terms of the Creative Commons Attribution Non-Commercial License (http://creativecommons.org/ licenses/by-nc/3.0) which permits unrestricted noncommercial use, distribution, and reproduction in any medium, provided the original work is properly cited. Copyright $\odot 2014$ by Korean Academy of Rehabilitation Medicine 


\section{INTRODUCTION}

Visual perception is a process that involves 'visual acceptance' and 'visual cognition' through interaction between the frontal lobe and parietal lobe in the human brain $[1,2]$. In this process, we accept the visual information from the environment. Next, we organize and interpret this information. Finally, we act on the basis of these processes [3-5].

About $35 \%-75 \%$ of patients with brain damage have particular impairments in visual perception [6-8]. These problems impair independent activities of daily living [1]. Furthermore these problems become major obstacles to post-stroke rehabilitation [9-14]. Therefore, a precise assessment of visual-perceptual function is important for planning a rehabilitation program. There are many assessment tools for visual-perceptual function being employed, such as the Motor-Free Visual Perception-3 (MVPT-3), Developmental Test of Visual Perception, Lowenstein Occupational Therapy Cognitive Assessment, and Assessment of Motor and Process Skills. Some tests, such as the Test for Visual-Perceptual Skills, were adapted specifically for Koreans, although these tests have only been standardized for children.

MVPT- 3 is the latest version and contains 65 questions from 6 categories: visual discrimination, form consistency, visual short-term memory, visual closure, spatial orientation, and figure ground [15]. The MVPT-3 has many advantages over other tools, as it helps physicians evaluate the visual-perceptual function regardless of motor function. The test is standardized for people aged 4-95 years, and it is conducted easily within 20-30 minutes [16]. Unlike the MVPT-2, which has been standardized for children, the scope of the MVPT-3 was expanded to adults in 2003. However, until now, the MVPT-3 has not been standardized for healthy Korean adults. Therefore, evaluations of visual-perceptual function in Korea have been done based on manuals and references from abroad. In particular, some previous studies have shown that the difference in raw scores between healthy Korean adults and foreign adults is significant.

In this study, we adapted the MVPT- 3 to Koreans and investigated the visual-perceptual function using the MVPT-3 in healthy Korean adults to provide reference values for clinical purposes.

\section{MATERIALS AND METHODS}

\section{Adaptation of the MVPT-3}

The Korean version of the MVPT-3 was developed through a cross-cultural adaptation process according to 6 steps including translation, reconciliation, back translation, cognitive debriefing, feedback, and final reconciliation $[16,17]$. A preliminary forward translation of the English version was done to produce the Korean version of the MVPT-3. Two experts translated the MVPT-3 stimuli based on related literature $[17,18]$. The translation was evaluated and modified by 7 experts through regular discussions. For example, 'flip the pancake' was changed to 'turn the rice cake upside down' which is an expression more familiar to Koreans. Other questions and evaluation methods were retained. A reverse translation was also done not by experts in this field but by proficient bilingual speakers of Korean and English. We clearly reviewed the adequacy of translation during these processes, and used it as a tool in this study.

\section{Standardization of the MVPT-3}

The target of this study was healthy Korean men and women aged $\geq 20$ years. We collected MVPT- 3 data from May 1, 2012 to October 19, 2012 from various facilities including universities, community organizations, regional health care facilities, and nursing homes in Seoul, Gyeonggi-do, Gyeongsangbuk-do, and Jeju-do. Participants were evaluated under similar conditions (quiet place and one-on-one). We reviewed the medical history and general information including age, sex, hometown, education level, and occupation for each subject. We performed the Edinburgh Handedness Inventory and the Korean version of the Mini-Mental State Examination (K-MMSE) [19]. The following subjects were excluded: people who had a score lower than the 2 percentile [20] on the K-MMSE; and those who had a history of brain injury, stroke, or other neurologic and/or neuropsychiatric disorders. The test was performed by people who had completed training on the given Korean version of the MVPT-3. They included physiatrists, occupational therapists, and graduate students in psychology.

Approval was obtained from the Institutional Review Board of Korea University Anam Hospital. The nature of the study was explained to the participants before the tests were administered, and informed consent was obtained in each case. 


\section{Statistical analysis}

The general characteristics of the participants, K-MMSE scores, and MVPT-3 scores are described using mean and standard deviation for continuous variables and frequency and percentage for categorical variables. Analyses of variance (ANOVAs) were used to ascertain the influence of age, years of education, sex, and cognitive function.

We divided the subjects into groups according to age and years of education. Ages were divided into 7 groups by decade. In addition, years of education were categorized as follows: $0,1-6,7-9,10-12$, and $\geq 13$ years. We performed ANOVA and Bonferroni post-hoc analysis between groups. Pearson product-moment correlation coefficients were obtained to evaluate the relationships between the MVPT- 3 scores, age, and years of education. We calculated Cronbach's $\alpha$ between the MVPT-3 categories for internal consistency. Content validity and concurrent validity were not calculated because these were verified by the original developer of the MVPT-

Table 1. Participant characteristics $(\mathrm{n}=321)$

\begin{tabular}{|lc}
\hline \multicolumn{1}{c}{ Characteristic } & Value \\
\hline Age (yr) & $51.05 \pm 1.17$ \\
\hline Sex (male:female) & $113: 208$ \\
\hline K-MMSE & $27.97 \pm 2.75$ \\
\hline $\begin{array}{l}\text { Edinburgh handedness inventory } \\
\text { (Rt:Lt:ambidexterity) }\end{array}$ & $302: 12: 7$ \\
\hline Years of education & \\
\hline 0 & 17 \\
\hline $1-6$ & 61 \\
\hline $7-9$ & 33 \\
\hline $10-12$ & 69 \\
\hline$\geq 13$ & 141 \\
\hline Regional distribution & \\
\hline Seoul & $50(15.6)$ \\
\hline Gyeonggi-do & $39(12.1)$ \\
\hline Chungcheong-do & $48(14.9)$ \\
\hline Gyeongsang-do & $111(34.6)$ \\
\hline Jeolla-do & $43(13.4)$ \\
\hline Gangwon-do & $15(4.7)$ \\
\hline Jeju-do & $6(1.9)$ \\
\hline Others & $9(2.8)$ \\
\hline
\end{tabular}

Values are presented mean \pm standard deviation or number (\%).

K-MMSE, Korean version of the Mini-Mental State Examination; Rt, right; Lt, left.
3. Finally, we compared our data with the results of the United States and Canadian studies $[4,21]$ by ANOVA to determine difference between races.

The statistical significance level was $p<0.05$. Statistical analyses were performed with the SPSS Statistics ver. 20 software package (IBM, Armonk, NY, USA).

\section{RESULTS}

\section{General participant characteristics}

Mean age and years of education of all 321 participants were $51.05 \pm 1.17$ years and $11.50 \pm 0.29$ years, respectively. The mean score on the K-MMSE was $27.97 \pm 2.75$ points (Table 1).

\section{MVPT-3 scores of healthy Korean adults}

Scores by category and internal consistency of the MVPT-3

The total mean score on the MVPT- 3 was $50.59 \pm 9.40$ points. The total score on the MVPT- 3 and scores for each category are shown in Table 2. The internal consistency of the MVPT- 3 was high and Cronbach's $\alpha$ between the MVPT-3 categories was 0.912 in this study.

\section{MVPT-3 scores according to age}

Age was significantly negatively correlated with total MVPT-3 score $(r=-0.669 \mathrm{p}<0.001)$. The ANOVA revealed a significant decrease in MVPT-3 score with age in each 10year category after 30 years old $(p<0.001)$ (Table 3$)$. After Bonferroni post-hoc analysis, the results led to a regrouping of the strata corresponding to a more significant intersection of age (5 groups: $20-49,50-59,60-69,70-79$,

Table 2. MVPT-3 scores for each category

\begin{tabular}{lr}
\hline \multicolumn{1}{c}{ Subgroup (total score) } & Mean \pm SD \\
\hline Visual discrimination 1 (8) & $7.48 \pm 1.09$ \\
Visual discrimination 2 (11) & $8.78 \pm 1.86$ \\
Form consistency (5) & $4.66 \pm 0.68$ \\
Visual short-term memory 1 (8) & $6.71 \pm 1.51$ \\
Visual short-term memory 2 (5) & $3.35 \pm 1.27$ \\
Visual closure 1 (13) & $10.69 \pm 2.14$ \\
Visual closure 2 (5) & $3.58 \pm 1.26$ \\
Spatial orientation (5) & $3.13 \pm 1.47$ \\
Figure ground (5) & $2.20 \pm 1.34$ \\
Total (65) & $50.59 \pm 9.40$ \\
\hline
\end{tabular}

MVPT-3, Motor-Free Visual Perception Test-3; SD, standard deviation. 
Table 3. MVPT-3 scores by decades of age

\begin{tabular}{lrrr}
\hline Age (yr) & N & Mean \pm SD (median) & p-value $^{*}$ \\
\hline $20-29$ & 91 & $56.73 \pm 5.04(57.69)$ & $<0.001$ \\
$30-39$ & 19 & $57.68 \pm 4.72(59.00)$ & \\
$40-49$ & 35 & $56.29 \pm 5.66(56.71)$ & \\
$50-59$ & 46 & $52.11 \pm 5.87(51.00)$ & \\
$60-69$ & 41 & $47.61 \pm 6.33(46.50)$ & \\
$70-79$ & 69 & $42.87 \pm 7.98(45.00)$ & \\
$\geq 80$ & 20 & $35.20 \pm 10.88(36.60)$ & \\
Total & 321 & $50.59 \pm 9.40(51.96)$ & \\
\hline
\end{tabular}

MVPT-3, Motor-Free Visual Perception Test-3; SD, standard deviation.

*p-value was calculated by analysis of variance (ANOVA).

Table 4. Result of post-hoc analysis of MVPT-3 scores according to age

\begin{tabular}{lrrr}
\hline Age (yr) & N & Mean \pm SD (median) & pc-value* $^{*}$ \\
\hline $20-49$ & 145 & $56.74+5.14(57.00)$ & $<0.001$ \\
$50-59$ & 46 & $52.11 \pm 5.87(51.00)$ & \\
$60-69$ & 41 & $47.61 \pm 6.33(46.50)$ & \\
$70-79$ & 69 & $42.87 \pm 7.98(45.00)$ & \\
$\geq 80$ & 20 & $35.20 \pm 10.88(36.60)$ & \\
Total & 321 & $50.59+9.40(51.96)$ & \\
\hline
\end{tabular}

MVPT-3, Motor-Free Visual Perception Test-3; SD, standard deviation.

*pc-value of intergroup comparison was calculated by Bonferroni correction.

$\geq 80$ years). Table 4 summarizes the results of the analysis assessing the influence of aging on MVPT-3 score.

\section{MVPT-3 score according to years of education}

The MVPT-3 score and participant years of education were positively correlated $(\mathrm{r}=0.715, \mathrm{p}<0.001)$. An ANOVA revealed a significant difference in MVPT-3 score among the years of education groups $(p<0.001)$. After a Bonferroni post-hoc analysis, the uneducated group showed extremely low scores on the MVPT-3 compared to those in the other groups (Table 5).

\section{MVPT-3 score, cognitive function, and sex}

No significant difference was observed in the MVPT-3 score according to sex $(\mathrm{p}=0.36)$. As the result of Pearson correlation test, we found MVPT-3 and K-MMSE scores were positively correlated $(\mathrm{r}=0.718, \mathrm{p}<0.001)$.
Table 5. Result of post-hoc analysis of MVPT-3 scores according to education level

\begin{tabular}{lrcc}
\hline Education level (yr) & N & $\begin{array}{c}\text { Mean } \pm \text { SD } \\
\text { (median) }\end{array}$ & $\begin{array}{c}\text { pc- } \\
\text { value* }^{*}\end{array}$ \\
\hline Uneducated (0) & 17 & $29.64 \pm 10.03(30.00)$ & $<0.001$ \\
$\begin{array}{l}\text { Primary and middle } \\
\text { school (1-9) }\end{array}$ & 94 & $43.81 \pm 7.87(45.00)$ & \\
$\quad$ High school (10-12) & 69 & $51.77 \pm 6.77(56.00)$ \\
College and over ( $\geq 12)$ & 141 & $56.31 \pm 5.29(57.16)$ \\
Total & 321 & $50.59+9.40(51.96)$ \\
\hline
\end{tabular}

MVPT-3, Motor-Free Visual Perception Test-3; SD, standard deviation.

*pc-value of intergroup comparison was calculated by Bonferroni correction.

Comparison with the MVPT-3 standardized studies in foreign countries

Mean MVPT-3 score was $49.07 \pm 10.74$ points in the United States and 50.40 \pm 9.47 points in Canada [21]. No significant differences were observed between scores in the different countries ( $\mathrm{p}=0.37$ for Korea vs. the United States; $\mathrm{p}=0.90$ for Korea vs. Canada).

\section{DISCUSSION}

The purpose of this study was to adapt and standardize the original version of the MVPT- 3 to Koreans and to investigate the characteristics of visual-perceptual function in healthy Korean adults. The internal consistency of the MVPT-3 in this study was as high as that in a previous study on the original version of the MVPT-3 [21]. Visual perception measured by the MVPT-3 was significantly influenced by age, years of education, and cognitive function.

As Korea is becoming an aging society, an increasing number of people suffer from various brain disorders including stroke and dementia. People are becoming more likely to have impaired visual perception as aging increases. Many patients with brain disorders are hugely frustrated and disappointed with these problems $[11,22,23]$. Visual-perceptual function is necessary for independent activities of daily living and gait function [1,9-11]. A significant correlation was revealed between visual-perceptual function and dysfunction of the nonparetic hand in a previous study [24]. Many tools are available to evaluate visual perception in western coun- 
tries. Among these, the MVPT- 3 is one of the commonly used assessment tool, as it can evaluate visual-perceptual function regardless of motor function within 20-30 minutes [16]. The MVPT is also the most used tool by occupational therapists in Korea for evaluating visual perception in patients with brain disorders [24]. However, the MVPT and its latest version, the MVPT-3, have not yet been standardized in healthy Korean adults. In this study, we provide MVPT-3 reference values according to age groups and years of education that will help with clinical and research use of the MVPT-3.

Our data of 321 healthy participants showed a significant decrease in MVPT-3 score with aging. The neurophysiological mechanisms responsible for changes in visual perceptual function in the elderly are poorly understood. Many studies [25] have found the effects of normal (non-pathological) aging on visual perceptual function in healthy elderly. Some recent neuroimaging studies have shown changes in the aging brain and networks activated during visual stimulation such as occipital and frontal regions [25].

Our results revealed a significant difference in the MVPT-3 score in the different education groups. In particular, the uneducated group showed a significantly lower score compared to that in the other groups. No significant difference was observed when we compared male and female scores. These results are consistent with the results of previous studies that standardized many occupational therapy screening tools including the MVPT-V $[5,15]$. Many other studies have reported a positive correlation between low education level and decreased cognitive function $[4,11]$. A study by Cerhan et al. [26] investigated test performance on a cognitive function battery, including the delayed word recall test, the digit symbol subtest of the Wechsler Adult Intelligence Scale, and the word fluency test. These scores were positively correlated with education level. Other studies have shown that education is a significant predictor of cognitive decline not only in the elderly but also in younger subjects $[27,28]$.

Finally, no significant differences were observed when we compared the results of this study to MVPT-3 standardization studies published in the United States and Canada [4,21]. A previous study performed in Korea reported conflicting results [29]. However, that study had a relatively small sample size and used the MVPT-2.

We collected and analyzed data of 321 Korean healthy adults. This is the first attempt to standardize the Korean version of the MVPT-3 and to set Korean normative references. However, a future study will be needed to provide expanded reference values including the pediatric population.

In summary, we found that visual perceptual function decreased with aging, lower education levels, and lower cognitive function. We obtained normative references for the MVPT-3 on an adult Korean population. Our results could be utilized to evaluate visual perception in patients with brain disorders. They will also help to plan a rehabilitation program for visual perceptual dysfunction and to assess clinical progress after treatment.

\section{CONFLICT OF INTEREST}

No potential conflict of interest relevant to this article was reported.

\section{ACKNOWLEDGMENTS}

This study was supported by the R\&D grant on rehabilitation by Korea National Rehabilitation Research Institute, Ministry of Health \& Welfare (No. 2012301).

\section{REFERENCES}

1. Titus MN, Gall NG, Yerxa EJ, Roberson TA, Mack W. Correlation of perceptual performance and activities of daily living in stroke patients. Am J Occup Ther 1991;45:410-8.

2. Chon JS, Chun SI, Yi YK, Jin MR, Lee BH. Correlation of visual perceptual dysfunction with brain lesion in stroke patients. J Korean Acad Rehabil Med 1997;21:253-8.

3. Bernspag B, Asplund K, Eriksson S, Fugl-Meyer AR. Motor and perceptual impairments in acute stroke patients: effects on self-care ability. Stroke 1987;18:10816.

4. Brown T, Elliott S. Factor structure of the Motor-Free Visual Perception Test-3rd edition (MVPT-3). Can J Occup Ther 2011;78:26-36.

5. Cooke DM, McKenna K, Fleming J. Development of a standardized occupational therapy screening tool for visual perception in adults. Scand J Occup Ther 2005;12:59-71. 
6. York CD, Cermak SA. Visual perception and praxis in adults after stroke. Am J Occup Ther 1995;49:543-50.

7. Friedman PJ, Leong L. Perceptual impairment after stroke: improvements during the first 3 months. Disabil Rehabil 1992;14:136-9.

8. Edmans JA, Lincoln NB. The frequency of perceptual deficits after stroke. Clin Rehabil 1987;1:273-81.

9. Chen Sea MJ, Henderson A, Cermak SA. Patterns of visual spatial inattention and their functional significance in stroke patients. Arch Phys Med Rehabil 1993;74:355-60.

10. Arena R, Gainotti G. Constructional apraxia and visuoperceptive disabilities in relation to laterality of cerebral lesions. Cortex 1978;14:463-73.

11. Mercier L, Audet T, Hebert R, Rochette A, Dubois MF. Impact of motor, cognitive, and perceptual disorders on ability to perform activities of daily living after stroke. Stroke 2001;32:2602-8.

12. Cate Y, Richards L. Relationship between performance on tests of basic visual functions and visualperceptual processing in persons after brain injury. Am J Occup Ther 2000;54:326-34.

13. Mazer BL, Korner-Bitensky NA, Sofer S. Predicting ability to drive after stroke. Arch Phys Med Rehabil 1998;79:743-50.

14. Khan S, Leung E, Jay WM. Stroke and visual rehabilitation. Top Stroke Rehabil 2008;15:27-36.

15. Mercier L, Desrosiers J, Hebert R, Rochette A, Dubois MF. Normative data for the motor-free visual perception test-vertical. Phys Occup Ther Geriatr 2001;19:3950.

16. Burtner PA, Qualls C, Ortega SG, Morris CG, Scott K. Test-retest reliability of the Motor-Free Visual Perception Test Revised (MVPT-R) in children with and without learning disabilities. Phys Occup Ther Pediatr 2002;22:23-36.

17. Beaton DE, Bombardier C, Guillemin F, Ferraz MB. Guidelines for the process of cross-cultural adaptation of self-report measures. Spine (Phila Pa 1976) 2000;25:3186-91.

18. Roh YH, Noh JH, Kim W, Oh JH, Gong HS, Baek GH. Cross-cultural adaptation and validation of the Kore- an version of the Oxford shoulder score. Arch Orthop Trauma Surg 2012;132:93-9.

19. Pyun SB, Hwang YM, Ha JW, Yi H, Park KW, Nam K. Standardization of Korean version of frenchay aphasia screening test in normal adults. J Korean Acad Rehabil Med 2009;33:436-40.

20. Crum RM, Anthony JC, Bassett SS, Folstein MF. Population-based norms for the Mini-Mental State Examination by age and educational level. JAMA 1993;269:2386-91.

21. Colarusso RP, Hammill DD. MTPT-3: Motor-Free Visual Perception Test. 3rd ed. Novato, CA: Academic Therapy Publications; 2003.

22. Hajek VE, Gagnon S, Ruderman JE. Cognitive and functional assessments of stroke patients: an analysis of their relation. Arch Phys Med Rehabil 1997;78:13317.

23. Skilbeck CE, Wade DT, Hewer RL, Wood VA. Recovery after stroke. J Neurol Neurosurg Psychiatry 1983;46:58.

24. Park SY, Yoo EY. The use of occupational therapy assessment tool by Korean occupational therapist. J Korean Soc Occup Ther 2002;10:99-108.

25. Spear PD. Neural bases of visual deficits during aging. Vision Res 1993;33:2589-609.

26. Cerhan JR, Folsom AR, Mortimer JA, Shahar E, Knopman DS, McGovern PG, et al. Correlates of cognitive function in middle-aged adults. Atherosclerosis Risk in Communities (ARIC) Study Investigators. Gerontology 1998;44:95-105.

27. Farmer ME, Kittner SJ, Rae DS, Bartko JJ, Regier DA. Education and change in cognitive function. The Epidemiologic Catchment Area Study. Ann Epidemiol 1995;5:1-7.

28. Evans DA, Beckett LA, Albert MS, Hebert LE, Scherr PA, Funkenstein HH, et al. Level of education and change in cognitive function in a community population of older persons. Ann Epidemiol 1993;3:71-7.

29. Chae SG. The compare study for visual-perception of brain damaged patients and normal people. J Korean Soc Occup Ther 2000;8:31-42. 